\title{
Does TB stigma affect emotion recognition? A study with a Portuguese sample
}

\author{
Teresa Nascimento ${ }^{1}$ \& Mauro Bianchi ${ }^{1,2}$ \\ ${ }^{1}$ Instituto Universitário de Lisboa (ISCTE-IUL), CIS-IUL, Lisboa, Portugal \\ ${ }^{2}$ HEI-Lab, Universidade Lusófona
}

\begin{abstract}
TB stigma constitutes a major barrier to disease control and social distress. This study aims to understand better the inherent social processes on the perception of emotions. Thus far, the specific role of TB stigma in this respect was not tested. We hypothesize that individuals in TB treatment (vs. a control non-clinical group) would identify more negative emotions in the faces of others, specifically rejecting emotions (e.g., disgust) when preoccupied with TB stigma. Two groups of participants completed a questionnaire with 23 faces, identified the emotions portrayed in the pictures, and reported their level of Stigma Consciousness, Interpersonal-Rejection Related to Stigma, and Rejection Sensitivity. Results show that the two groups significantly differ in their perceptions of negative emotions: participants in treatment identify less disgust and more sadness, fear, and anger versus the control group. Findings are discussed concerning the literature on stigma and its consequences.
\end{abstract}

\section{Keywords: Stigma; Emotions; Emotion Recognition; Tuberculosis.}

0 estigma da tuberculose afeta o reconhecimento de emoções? Estudo realizado com uma amostra portuguesa: 0 estigma da Tuberculose causa sofrimento social e é uma barreira importante no seu controlo. Pretende-se compreender melhor os processos sociais, a ele subjacentes, na perceção de emoções. Até agora, o papel do estigma da Tuberculose a este respeito não foi testado. Como hipótese propõe-se que os indivíduos em tratamento para a Tuberculose (versus grupo de controlo) identificarão mais emoções negativas na face dos outros, especialmente emoções de rejeição (i.e., nojo) quando preocupados com o estigma., Dois grupos de participantes responderam a um questionário com 23 faces onde identificaram a emoção, a Consciência do Estigma, Rejeição Interpessoal Relacionada com o Estigma e Sensibilidade à Rejeição. Mostra-se que os dois grupos diferem na perceção de emoções negativas: os doentes em tratamento identificam menos nojo, e mais tristeza, medo e raiva que o grupo de controlo. Os resultados são discutidos à luz da literatura do estigma e das suas consequências.

Palavras-chave: Estigma; Emoções; Reconhecimento de emoções; Tuberculose.

Tuberculosis (TB) is still a severe public health problem and continues to be one of the World Health Organization (WHO) top concerns regarding infectious diseases. TB is the ninth leading cause of death worldwide and the leading cause from a single infectious agent, ranking above HIV/AIDS (WHO, 2017). An estimated 10.4 million people got ill with TB in 2016. In Portugal, we have fallen below the 20 cases per 100,000 population barrier, but the situation is still a cause for disease control concern (WHO, 2017). One main reason for the slow decline in the prevalence of this disease worldwide could be that the focus of TB control has been a biomedical approach (Atre et al., 2011). The psychosocial and cultural roles have been neglected in the treatment of these patients. Indeed, several studies have pointed out the need to consider the social burden of illness and distinctive features of health-related stigma (Weiss \& Ramakrishna, 2006) to prevent or mitigate its adverse consequences.

TB stigma has an enormous effect on individuals' daily lives and could be a determinant factor for their withdrawal from treatment, independent of their social class and gender (Atre et al., 2011; WHO, 2017). Not all individuals experience TB stigma in the same way, due to their characteristics and to the context of their social interactions. Several authors have noticed that being a target of stigma can affect various psychological processes involved in social interaction, from monitoring thoughts and behavior (Newheiser \& Barreto, 2014) to perception of emotions in the facial expressions of others (Inzlicht et al., 2008).

${ }^{1}$ Correspondence address: Teresa Maria Nascimento, Avenida das Forças Armandas - Edifício ISCTE, CIS-Iscte (sala2W08), 1649-026 Lisboa. E-mail: Teresa_Nascimento@iscte-iul.pt 
During social interactions, individuals look for clues of rejection or acceptance (Inzlicht et al., 2008) on the faces of others. The face is their focus of attention when interacting with others, so individuals have a unique ability to read and decode facial expressions, especially if these are intense and clear. If facial expressions are ambiguous and subtle, their recognition or perception may become a more complex process (Inzlicht et al., 2008). Understanding the impact of TB stigma on emotion recognition on the faces of others is the main goal of this study.

\section{TB stigma}

A social stigma is a social identity devalued by others in a particular context (Dovidio et al., 2003). It affects an internal part of the self, but it is also relational, in the sense that others perceive and interact in a biased way towards the stigmatized target (Dovidio et al., 2003). No characteristic of an identity is a stigma per se because what may be the object of stigma in a given social context may not be in any other context (Newheiser \& Barreto, 2014). Therefore, stigma is socially determined and with cultural and temporal variations on the characteristics or parts of stigmatized identity.

Stigma is a powerful phenomenon that affects the quality of life of stigmatized people, interfering in their intergroup and ingroup relations and affecting their self-esteem and mental capacities. Its effects can persist even when the source of stigmatization is not contextually salient or in a non-stigmatizing context, given that a person may still feel stigmatized (Steele \& Aronson, 1995). Because they deal chronically with stigma, members of stigmatized groups tend to be more sensitive to certain potentially discriminatory clues. Indeed, the expectation of being stigmatized makes people more vigilant, more alert, more seeking of rejection signs (Dovidio et al., 2003) and forces them to make a tremendous mental effort that results in the drainage of cognitive resources and the weakening of self-control (i.e., ego depletion) (Inzlicht et al., 2006; Newheiser \& Barreto, 2014).

In the last few decades, disease-related stigma, particularly with mental illness (e.g., Wahl, 1999) and HIV (e.g., Daftary, 2012), has been strongly emphasized, demonstrating the need to understand better stigmatization linked to the disease.

In a special section of The Lancet, reporting a stigma and health international conference that took place in 2001, Weiss and Ramakrishna (2006) defined health-related stigma as "a social process or related personal experience characterized by exclusion, rejection, blame, or devaluation that results from experience or reasonable anticipation of an adverse social judgment about a person or group identified with a particular health problem." This conference was an important milestone from which several studies were developed. The studies regarding TB-related stigma revealed: gender issues in access to health care - women do not seek medical help as often as men for fear that their male partners will abandon them or not marry them (Juniarti \& Evans, 2011; Karim et al., 2007). Fear of prejudice and discrimination emerged from several studies which cause withdrawal from social contact and the shunning of contact with other people (Juniarti \& Evans, 2011; Steele \& Aronson, 1995). TB patients often conceal their disease to avoid adverse social reactions (Juniarti \& Evans, 2011. The association between TB and HIV infection can cause a double stigma (Daftary, 2012). People have misconceptions and false beliefs associated with the disease, i.e., an exaggerated fear of spreading the disease or believing that TB is a hereditary disease (Atre et al., 2011). People associate TB and poverty (Baral et al., 2007; Vieira, 2011), both because often TB patients share the same deprived environments and because their immune system is diminished due to poor nutrition. TB patients diminished self-esteem due to the disease, resulting in emotional suffering (Atre et al., 2011). TB patients are isolated socially, both outside the family, where friends and colleagues may avoid them, and inside the family, where they may be forced to eat and sleep separately (Juniarti \& Evans, 2011). Patients often isolate themselves to avoid infecting others and to avoid uncomfortable situations such as being shunned or becoming the subject of gossip. Being either a patient or an ex-patient is likely to affect employment and employment prospects (Karim et al., 2007).

Stigma and consequent discrimination have a double impact on TB control. Firstly, concerns about being identified as a person with TB make it more difficult for people to seek care because of the TB diagnostic process's public nature. By delaying seeking care, these people may develop more severe symptoms, meaning they will be more challenging to treat. As they remain infectious for longer, they are more likely to transmit the disease to others. Secondly, concerns about stigma and discrimination for TB make it more difficult for patients to continue with care because their fears of being identified as having or having been infected with TB hinder their access to services. Again, this can lead to more severe symptoms and increased transmission.

To avoid this kind of suffering, people often conceal their illness (Newheiser \& Barreto, 2014) or cover up the type of condition they suffer from while maintaining the risk of transmission of the disease, avoid seeking medical help, or tend to not comply with the treatment until the end, leading to an increasing number of patients with multidrug-resistant TB. 


\section{Perception of emotions}

As previously noted, individuals use facial expressions of emotions they observe in others as sources of information that influence, regulate, and model their behavior (Ekman et al., 1969), having a critical role in social interaction. Facial expressions can induce conscious and unconscious behavior.

It is believed that all human beings in all different cultures communicate seven basic emotions with the same facial expressions - happiness, surprise, fear, disgust, contempt, anger, and sadness and that these facial muscles' movements are understood universally by their biological and evolutionary origins (Darwin, 1890; Ekman et al., 1969).

Although decoding facial expressions in others is not a linear process, it implies a two-way communication involving an expresser and a perceiver, influenced by the expresser's intensity of expression, and the perceiver's stereotypes, prejudice, and group membership. Regarding perceptions of facial affect, research on social categorization and emotion recognition has shown a stereotypical bias in the perception of emotions in faces. Indeed, consistent with the idea that stereotypical associations influence emotion recognition, Bijlstra and colleagues found that the more Dutch participants associated Moroccans with anger and the Dutch with sadness, the more readily they decoded anger on Moroccan male faces and sadness on White Dutch male faces. Recent research has highlighted how group membership shapes face perception. For example, a research project (Dotsch et al., 2008) found that individuals' visual representations of the typical European face were biased toward their own nation's typical appearance. Other research has shown how stereotypical expectations bias the perceived appearance of stigmatized outgroup members in the direction of the stereotypes associated with their group. For example, Dutch participants' representations of ethnic faces were related to their level of prejudice. The more prejudiced participants were, the more criminal looking their prototype of a Moroccan face was (Dotsch et al., 2008).

Based on previous findings and theoretical background, we predict that TB patients in treatment, because they often encounter negative emotions, displayed on the faces of others (e.g., disgust as avoidance-disease emotion; Oaten et al., 2009), will be more sensitive to these clues (Atre et al.,2011). TB patients will easily decode these clues if they are open, unmistakable, and non-ambiguous (Ekman et al., 1969). When clues are ambiguous, emotional expressions' interpretation becomes more complex and dynamic (Hassin et al., 2013). This study aims to understand how TB patients in treatment would appraise the display of ambiguous emotions compared to a control group.

Regarding negative emotions, we highlight fear, anger, sadness, and disgust. Fear denotes an intense urge to defend oneself and the presence of some threat from which we must move away (Marsh et al., 2005). Anger is the emotion that elicits avoidance because its expression is threatening to the perceiver (Marsh et al., 2005). Sadness is generally associated with the appraisal of permanent loss of a person or object of importance to the self (Ambady \& Gray, 2002). Finally, disgust is a type of emotion universally recognized and experienced (Ekman et al., 1969) and appears to have common inducers in diverse cultures (Curtis \& Biran, 2001). Foods or body parts are the inducers of disgust for which the brain is directly shaped by natural selection, probably to avoid pathogens. Avoiding pathogens brings a considerable advantage from the adaptive point of view because it allows individuals to detect likely infection sources and avoid contact with them. This is an enormous benefit because it enables the individual to live longer, mate, and procreate. The pressure exerted by the pathogens led to creating a system of socially acquired and expanded hygiene behavior - disgust as a disease avoidance mechanism (Oaten et al., 2009). These hygiene behaviors have a component of social interaction and learning of group behaviors, aiming to reduce various pathogens' transmission (Curtis \& Biran, 2001). In this line of reasoning, there is a correspondence between cues that evoke disgust and cues that signal disease (Curtis \& Biran, 2001).

\section{Individual differences}

People are different from each other; they differ in how they relate to others, perceive and assess situations in their social interaction, and in the extent to which they expect to suffer from prejudice. Individuals who are chronically prejudiced and stigmatized are aware of the possibility of being discriminated against in certain situations, so they expect this phenomenon in their social interaction even in non-stigmatized contexts. Fear of having a negative stereotype about their group as personal traits is called Stereotype Threat (Steele \& Aronson, 1995). For example, in an intellectual aptitude test, black students experienced academic underperformance compared with their white colleagues when told that it was an intellectual aptitude test (Steele \& Aronson, 1995). This dimension evokes the stereotype of the intellectual inferiority of their group.

Consequently, stigmatized individuals can create a pattern of intergroup rejection. Their fear of being socially devalued may lead them to look for clues of rejection in the faces of others. Perhaps, individuals from stigmatized groups tend to be more sensitive to discrimination cues than individuals from non-stigmatized groups (i.e., dominant or majority groups) because of this vigilance. Inzlicht et al. (2008), 
for example, found that expectations of prejudice were associated with the tendency to see more rejection (i.e., contempt) emotions and for longer on faces of men - outgroup, than in the faces of women - ingroup. Also, past exposure to prejudice and discrimination can shape individual differences among stigmatized individuals. On the one hand, individuals who have been exposed frequently to prejudice and discrimination might be more educated about the forms and frequencies it can take, and, on the other hand, they might be more motivated to search for it, i.e., on the faces of meaningful others

People also differ in the extent to which they are sensitive to stigma. Stigma consciousness (Pinel, 1999 ) is one characteristic that influences people to perceive and assess stigma. Pinel (1999) found evidence that women who were highly conscious of stigma paid more attention to stereotype threat clues. Another feature is rejection sensitivity, described by Downey and Feldman (1996), a cognitive-affective processing disposition to expect, readily perceive, and overreact to rejection. Indeed, these researchers found that people who expect to be rejected perceive more rejection in ambiguous behavior. Interpersonal rejection related to stigma is another characteristic that influences how people interact socially. Wahl (1999) did a survey of mental health consumers' who experience interpersonal stigma. He found that people who were afraid of the stigma associated with their illness did not apply for jobs or seek health care and education, leading to social isolation.

\section{STUDY}

As mentioned earlier, psychological states, individual differences, group membership, and specific contexts can shape the perception of emotions. However, despite the most recent scientific evidence, little is known from the point of view of stigmatized individuals. To our knowledge, only Inzlicht et al. (2008) have shown that individuals who chronically experience stigma were biased in perceiving emotions in facial expressions of outgroup members, especially the emotion of contempt known to be related to interpersonal rejection. We trust that we contribute to the international literature on this topic with this work because we bring the stigmatized person's point of view. Based on the previous findings of Inzlicht et al. (2008) and the theoretical model of disgust as a mechanism of protection against diseases (Curtis \& Biran, 2001), we believe that TB patients who chronically expect to be treated prejudicially will be biased in the perception of negative emotions specifically disgust. One at a time, a group of participants watched a series of pictures showing ambiguous faces and unambiguous faces. The participants' main task was to choose the corresponding emotion from a list of seven emotions. Ambiguous faces are of paramount importance to this study because we want to understand precisely how individuals belonging to stigmatized groups perceive discrimination through very subtle clues like ambiguous emotions expressed by others.

\section{Objectives and hypothesis}

Previous research has pointed out how stigma can affect emotion recognition (Inzlicht et al., 2006). This study aims to understand the impact of TB stigma on emotion recognition in the faces of others, particularly the emotion of disgust. Indeed, as Oaten et al. (2009) propose, disgust evolved from a system of protection against contagious diseases. TB patients have a contagious disease that is profoundly stigmatizing, influenced by beliefs of poverty and lack of hygiene over several generations (Vieira, 2011) and, therefore, related to emotions such as repulsion and disgust. Consequently, as part of a stigmatized group, we hypothesize that, in general, people who belong to a stigmatized group attribute more negative emotions to others compared to a control group, and this effect will be particularly strong for disgust recognition. Based on previous research investigating individual differences in emotion recognition, we expect that people who belong to a stigmatized group who are more preoccupied with stigma will identify more faces expressing disgust than a control non-clinical group.

\section{METHOD}

\section{Ethics Committee for Health}

Given the specificity of the sample and type of participants to be part of our study, because they were TB patients and answered the questionnaire in the same place where they have their medical appointments, authorization was requested from to CDP Coordinator José Miguel Carvalho MD, from Mrs. Diana Leiria Executive Director of ACES Lezíria, and the Ethical Committee for Health from Administração de Saúde de Lisboa e do Tejo, which was granted by the three entities.

\section{Participants}

Thirty-four individuals in treatment for TB in Centro de Diagnóstico Pneumológico from Santarém, Portugal, (16 female and 18 males; $\mathrm{M}_{\mathrm{age}}=48.82$ years; age range: 18 - 80 years) were asked to complete a 
questionnaire after their monthly medical check. Diagnosis of TB (e.g., "How long since you were diagnosed with TB?") varied from less than a month to one year (M = 5.1 months; SD = 3.26).

Thirty-four individuals (non-clinical control group), recruited online via social media, completed the questionnaire (26 female and 8 males; $M_{\text {age }}=46.06$ years; age range: 20 - 65 years).

\section{Procedure}

TB patients in treatment at CDP Santarém were invited to participate in our study after their monthly medical check. Individuals who agreed to participate were referred to an office with a computer connected to the internet where, in individual sessions, they answered the online questionnaire.

In the first task, we asked participants to answer the question "What emotion do you see on this person's face?" for each of 23 pictures: four pictures with neutral expression, 14 pictures with ambiguous expressions, and five pictures with unambiguous expressions (Fig.1). To answer the question, participants had to choose one corresponding emotion from a list of seven emotions - happiness, sadness, anger, disgust, surprise, fear, and contempt. There were only these seven choices available, with no opportunity to add an emotion. We chose as the main emotions disgust and contempt because they are rejection emotions toward the outgroup. Furthermore, disgust is an emotion related to contagious diseases, so we expect an effect on this type of emotion even though contempt serves the purpose of control. Neutral faces and unambiguous facial emotions were selected to explore if TB patients and the control group choose the same emotions and test each group's accuracy.

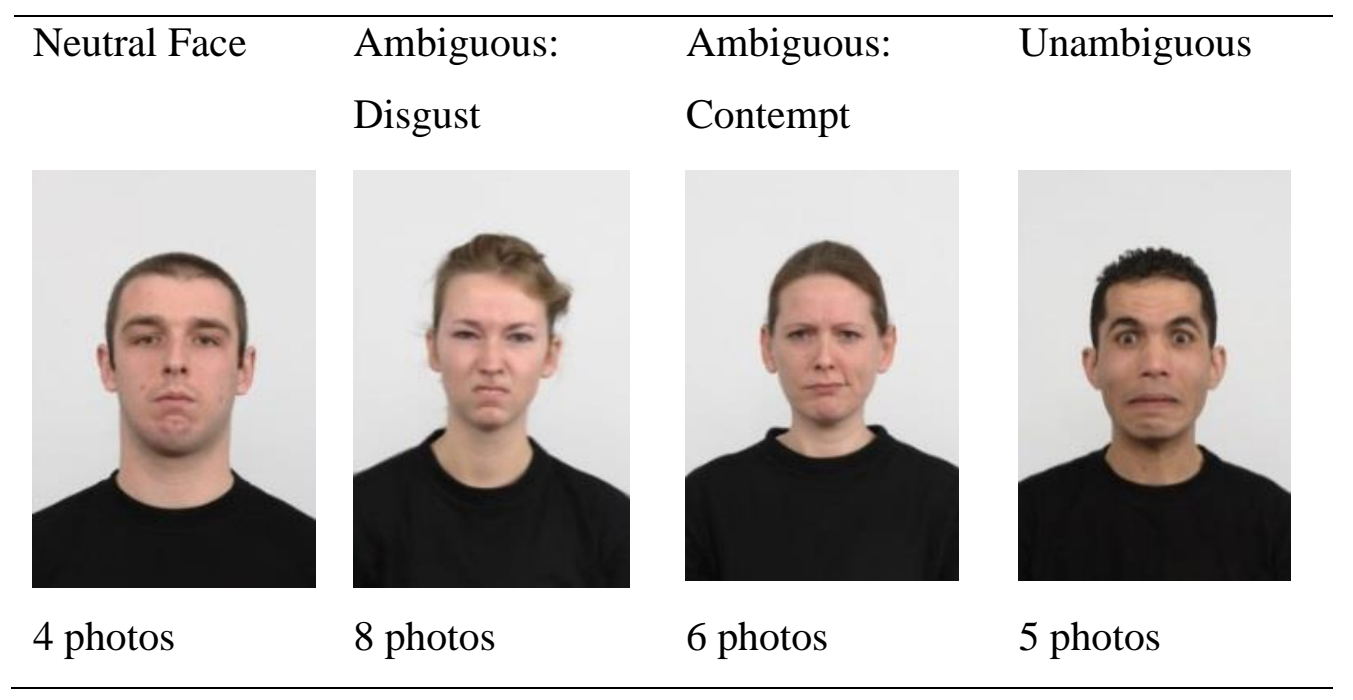

Figure 1. Four examples of faces, one from each type of photo.

After that, participants answered a three-scale questionnaire: Stigma consciousness scale, Stigma related interpersonal rejection scale, and Rejection sensitivity scale (short version), as well as socialdemographic questions. Lastly, the researcher had a short debriefing session with each participant.

All participants were informed about the nature and goals of the study, the voluntary nature of their participation, and the guarantee of confidentiality and anonymity of the data.

Individuals from the control group were recruited from social media, and they answered the same online questionnaire; an email contact was made available to clarify any doubts.

\section{Materials}

We selected 160 pictures of adults with frontal gaze and $90^{\circ}$ head orientation from the Radboud Faces Database (Langner et al., 2010). Radboud Faces Database is a set of pictures of 67 models displaying eight emotional expressions. Then, we selected 2 female pictures with Neutral expression, 1 female picture expressing Anger, and 1 female picture expressing Happiness; 2 male pictures with Neutral expression, 1 male picture expressing Contempt, 1 male picture expressing Disgust, and 1 male picture expressing Fear. With those 9 pictures, we created 14 ambiguous pictures by morphing them using the software Fantamorph5 Standard: Anger and Disgust, Happiness and Disgust, Contempt and Disgust, Fear and Disgust, Anger and Contempt, Happiness and Contempt, Fear and Contempt (see Table 1). 
Table 1. Sequence of pictures.

\begin{tabular}{lccc}
\hline Facial Expression & $\begin{array}{c}\text { Number of female } \\
\text { pictures }\end{array}$ & $\begin{array}{c}\text { Number of male } \\
\text { pictures }\end{array}$ & Total \\
\hline Neutral & 2 & 2 \\
Morphing Disgust + Anger & 1 & 1 \\
Morphing Disgust + Happiness & 1 & 1 \\
Morphing Disgust + Fear & 1 & 1 \\
Morphing Disgust + Contempt & 1 & 1 \\
Morphing Contempt + Anger & 1 & 1 \\
Morphing Contempt + Happiness & 1 & 1 \\
Morphing Contempt + Fear & 1 & 1 \\
Contempt & 0 & 1 \\
Anger & 1 & 0 \\
Disgust & 0 & 1 \\
Happiness & 1 & 0 \\
Fear & 0 & 1 \\
Total & 11 & 12 \\
\hline
\end{tabular}

The Stigma Consciousness Scale (Pinel, 1999), adapted for TB patients and adapted for the control group, evaluates the degree to which each person expects to be stigmatized and discriminated against because of their illness. Participants rated their agreement with 10 items (e.g. "I'm concerned that others see my behavior as the behavior of those with TB" for TB patients group; "I think people with TB fear that their behavior will be seen as typical of people with this disease.", for the control group) on a 7-point Likert scale ranging from 1 - Totally disagree to 7 - Totally agree. Higher score indicates high stigma consciousness, lower score indicates low stigma consciousness (Cronbach's $\alpha=.89, M=4.51, S D=1.43$ patients, and Cronbach's $\alpha=.57, M=4.28, S D=.64$ - control group). As far as this scale is concerned, we didn't find a significant difference between the two groups $F(1,66)=.72, p=.39, \eta^{2}=.01$.

The Stigma Related Interpersonal Rejection Scale (Wahl, 1999), adapted for TB patients and adapted for the control group, evaluates the degree to which each TB patient feels interpersonal rejection related to their illness. Participants rated their agreement with 9 items (e.g., "I have worries that others view me unfavorably because I'm a TB patient.", for TB patients group; “TB patients are concerned that others have an unfavorable image of them because they have TB.," for the control group) on a 7 points Likert scale ranging from 1 - Totally disagree to 7 - Totally agree. A higher score indicates high sensitivity to TB related interpersonal rejection; a lower score indicates low sensitivity to TB - related interpersonal rejection. (Cronbach's $\alpha=.70, M=3.80, S D=1.05$ - patients, and Cronbach's $\alpha=.56, M=4.04, S D=.63$ control group). We didn't find a significant difference on this scale between the two groups $F(1,66)=1.27$, $p=.26, \eta^{2}=.02$.

The Rejection Sensitivity Scale (short version) (Downey \& Feldman, 1996) evaluates the degree of anxiety and concern about rejection threat and expectations of support in social situations. Participants had to imagine a hypothetical situation where they must ask a favor from someone close to them, rejection being a possibility, after which we asked them to answer two questions: "How concerned or anxious would you be about how the other person would respond?", "How do you think the other person would be likely to respond?" on a 7 points Likert scale ranging from 1 - very unconcerned to 7 - very concerned and ranging from 1 - very unlikely to 7 - very likely, respectively. (Cronbach's $\alpha=.78, M=5.42, S D=2.49$ patients and Cronbach's $\alpha=.66, M=4.60, S D=2.13$ - control group). As far as this scale is concerned we didn't find a significant difference between groups $F(1,66)=2.12, p=.15, \eta^{2}=.03$.

\section{RESULTS}

\section{Recognition of emotion}

We computed seven ANOVA tests, one for each emotion. Participants' choices of each emotion (happiness, sadness, fear, surprise, disgust, anger, and contempt) were analyzed through an ANOVA 4 (type of photos: neutral, ambiguous involving disgust, ambiguous involving contempt, and unambiguous) X 2 (groups: TB patients and control group) with the former factor as within-subject variable and latter factor as betweensubject variable. Choices of emotions were calculated as the ratio of the number of times a specific emotion 
was chosen. Ratios could range between 0 (a specific emotion was never chosen) to 1 (a specific emotion was always chosen).

As far as disgust is concerned, we found that participants' overall choice of disgust was affected by the type of photos, $F(3,63)=61.51, p<.001, \eta^{2}=.482$. Also, we found an overall significant difference between the patients and the control group, $F(1,66)=6.73, p=.012, \eta^{2}=.09$, showing that TB patients attributed on average $(M=.08)$ less disgust to describe the faces than the participants in the control group $(M=.12)$. Importantly, these effects were qualified by a significant interaction between groups and type of photos, $F(3,63)=4.72, p<.01, \eta^{2}=.07$. We calculated post-hoc pairwise comparisons. As can be seen in Figure 2, we found a significant difference between the groups on ambiguous photos involving disgust; that is, participants in TB treatment $(M=.18)$ attributed less disgust to these faces than participants in the control group $(M=.30), F(1,66)=7.18, p=.009, \eta^{2}=.10$. Also, when unambiguous pictures were involved, participants in TB treatment $(M=.12)$ attributed less disgust to these faces than participants in the control group $(M=.17)$. This difference fell short of the conventional level of significance, $F(1,66)=3.24, p=.076$, $\eta^{2}=.05$.

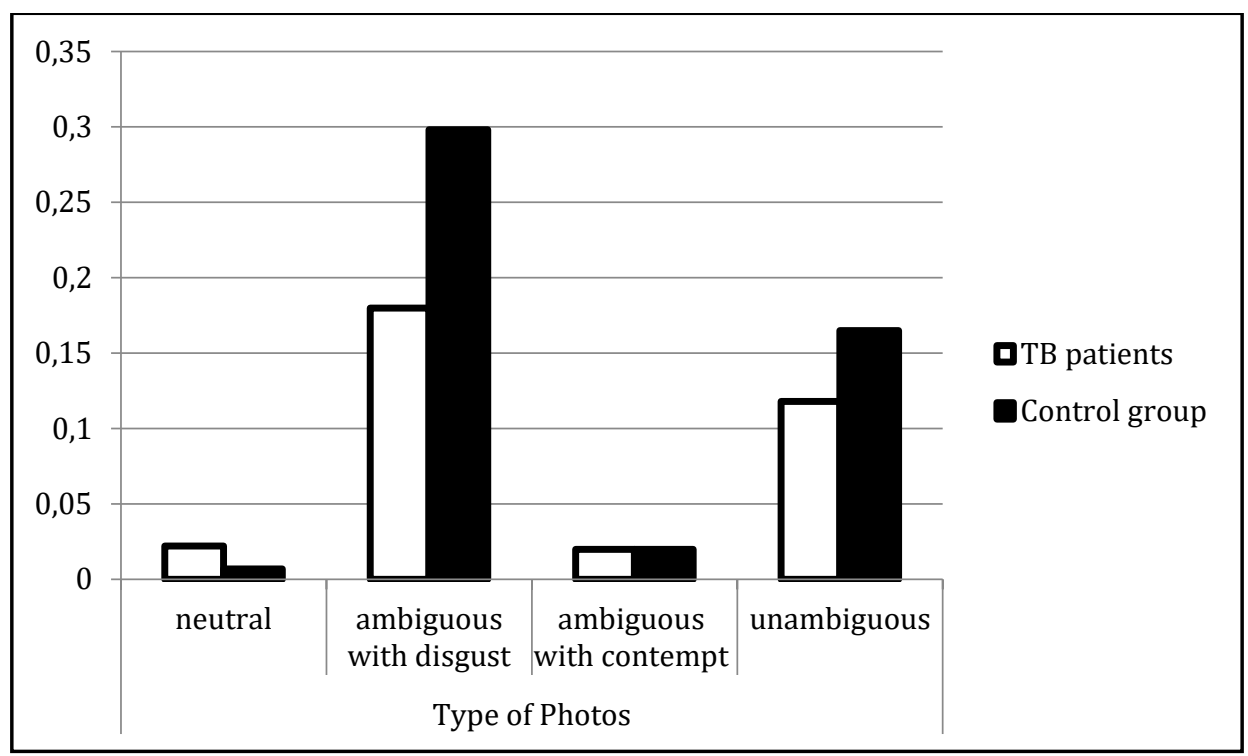

Figure 2. Average ratio of choice of disgust by type of photo and group.

For the emotion of anger, we found a significant effect on overall type of photos, $F(3,63)=47.05, p<$ $.001, \eta^{2}=.42$. This effect was qualified by an interaction between type of photo and group, $F(3,63)=2.93$, $p=.035, \eta^{2}=.04$. Pairwise comparison shows a significant difference between the groups on ambiguous photos involving disgust, that is, participants in TB treatment $(M=.18)$ attributed more anger to these faces than participants in the control group $(M=.09), F(1,66)=9.80, p=.003, \eta^{2}=.13$ (see Figure 3 ).

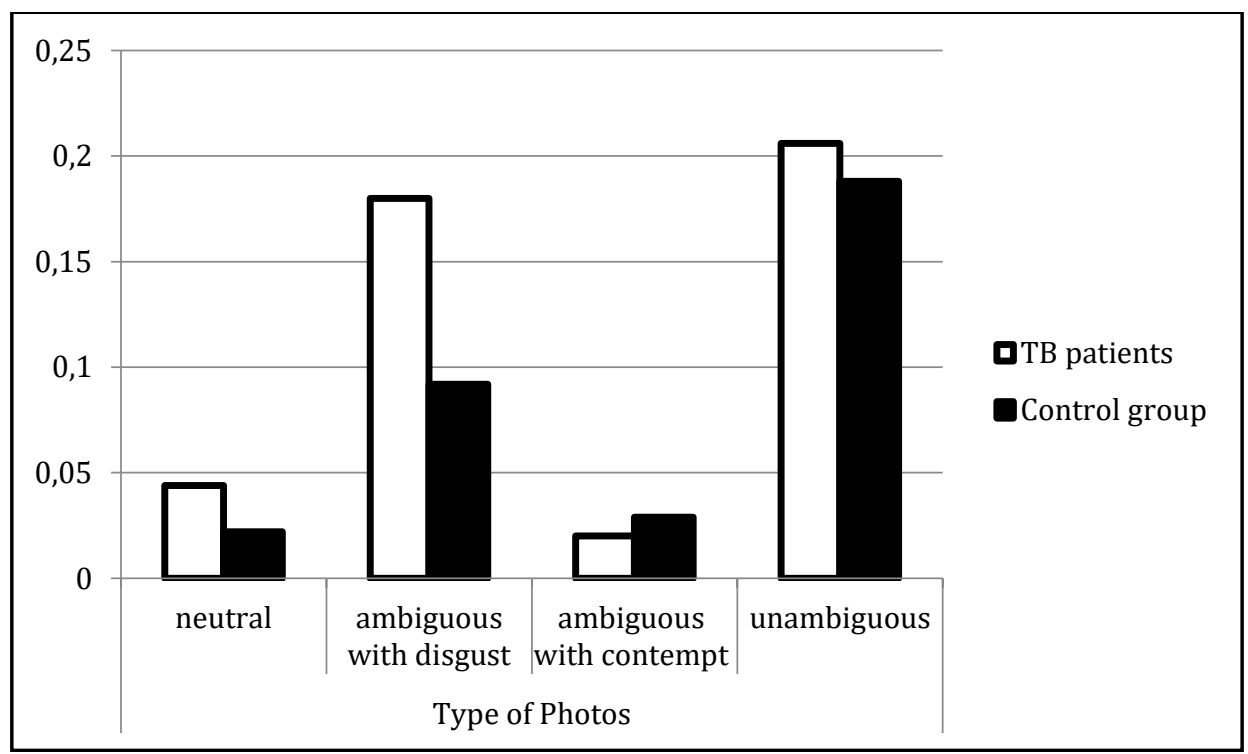

Figure 3. Average ratio of choice of anger by type of photos and group. 
As far as fear is concerned, we found a significant effect on overall type of photos, $F(3,66)=10.87, p$ $<.001, \eta^{2}=.14$. This effect was qualified by an interaction between type of photo and group, $F(3,63)=3.49$, $p=.017, \eta^{2}=.05$. Pairwise comparison shows a significant difference between the groups on neutral photos, that is, participants in TB treatment $(M=.13)$ attributed more fear to these faces than participants in the control group $(M=.04), F(1,66)=7.22, p=.009, \eta^{2}=.10$ (see Figure 4).

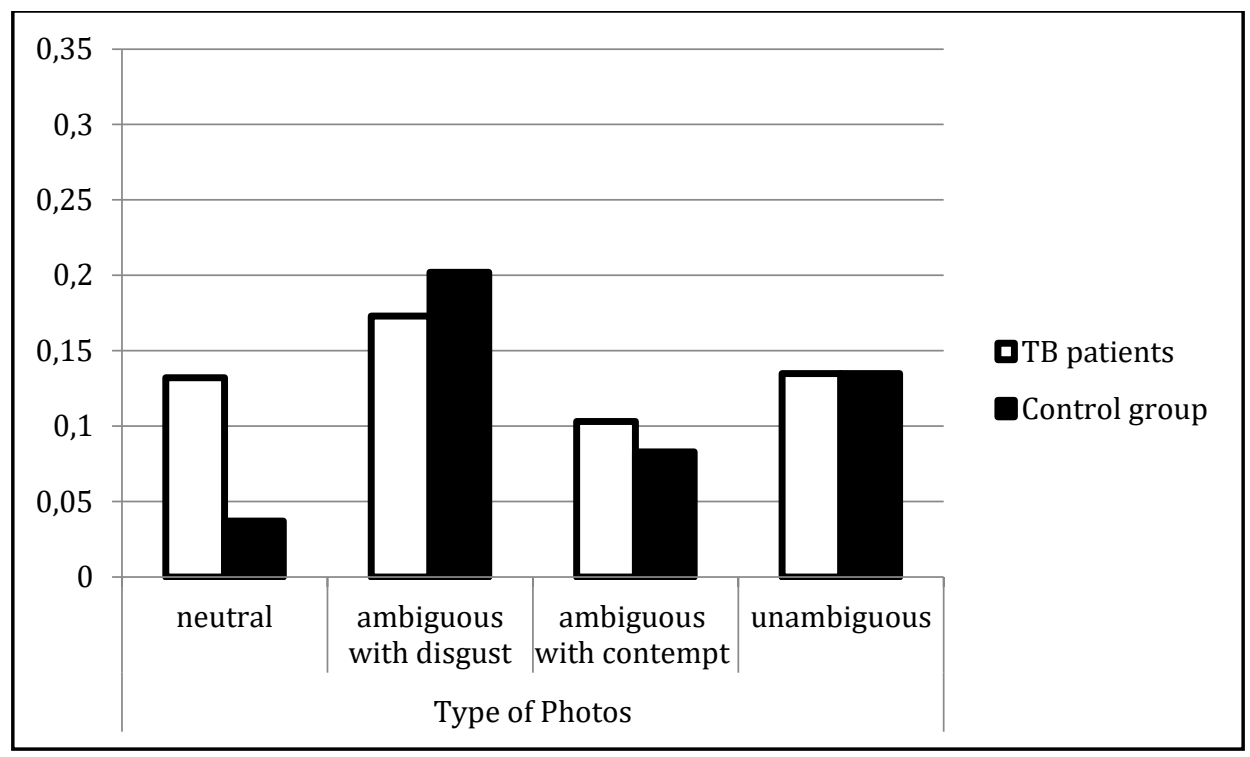

Figure 4. Average ratio of choice of fear by type of photo and group.

For the emotion of happiness, we found a significant effect on overall type of photos, $F(3,66)=72.28$, $p<.001, \eta^{2}=.52$. This effect was qualified by an interaction between type of photo and group, $F(3,63)=$ $4.19, p=.007, \eta^{2}=.06$. Pairwise comparison shows a significant difference between the groups on neutral photos, that is, participants in TB treatment $(M=.13)$ attributed less happiness to these faces than participants in the control group $(M=.24), F(1,66)=4.10, p=.047, \eta^{2}=.06$ (see Figure 5).

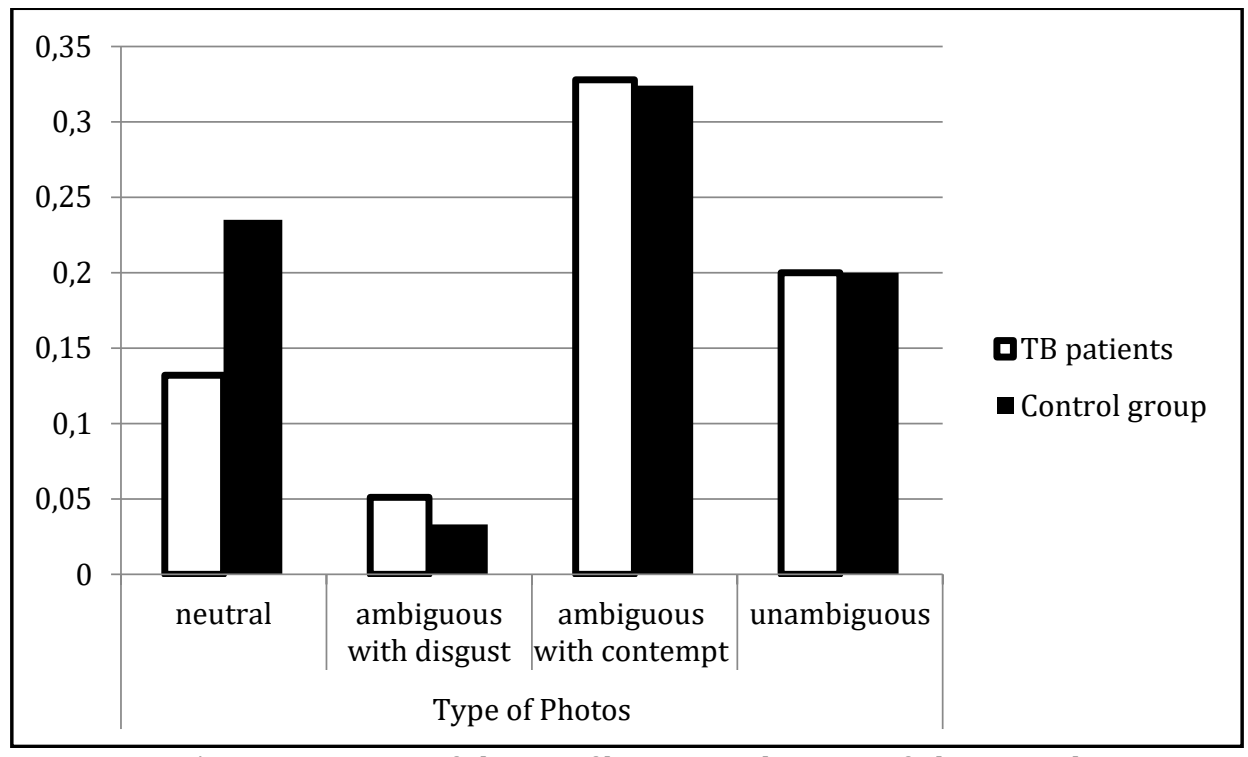

Figure 5. Average ratio of choice of happiness by type of photos and group.

For the emotion of sadness, we found a significant effect on overall type of photos, $F(3,66)=26.52$, $p<.001, \eta^{2}=.29$. This effect was qualified by an interaction between type of photo and group, $F(3,63)=$ $4.96, p=.002, \eta^{2}=.07$. Pairwise comparison show a significant difference between the groups on neutral photos, that is, participants in TB treatment $(M=.36)$ attributed more sadness to these faces than participants in the control group $(M=.17), F(1,66)=11.35, p=.001, \eta^{2}=.15$ (see Figure 6). 


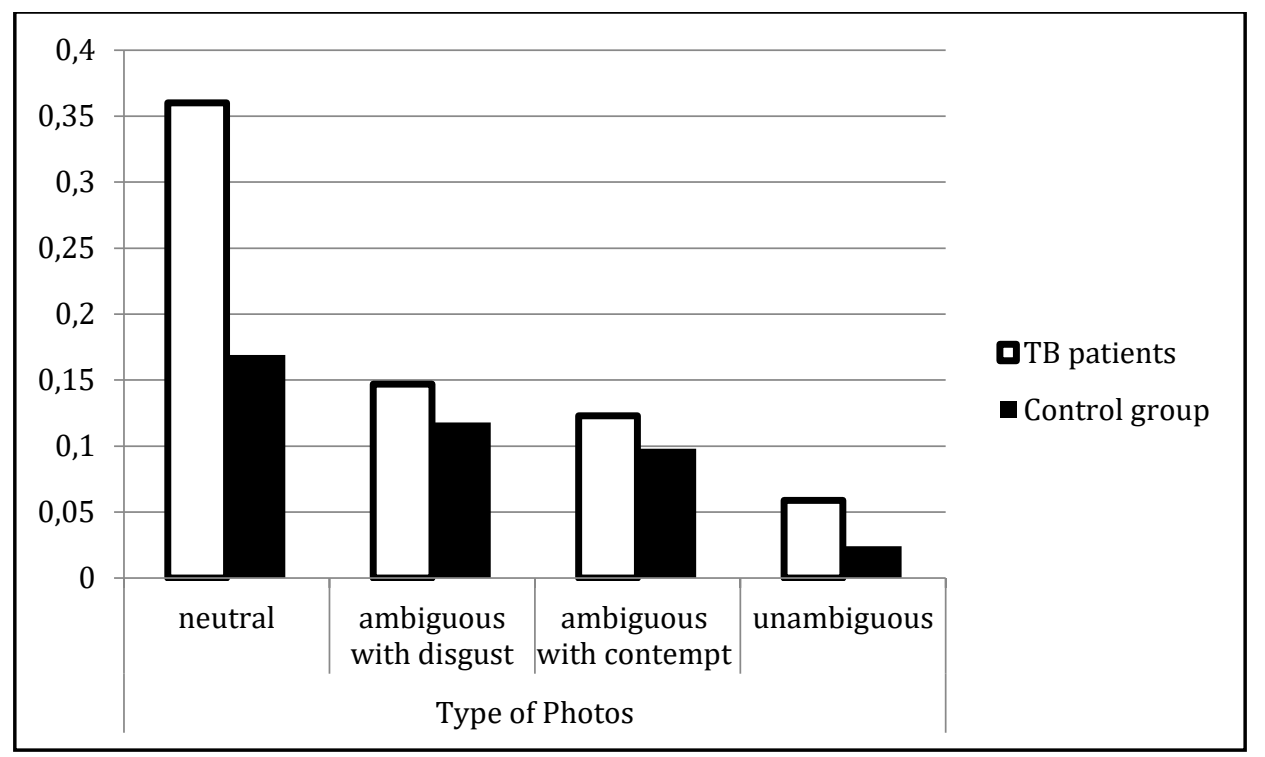

Figure 6. Average ratio of choice of sadness by type of photos and group.

For the emotion of contempt and surprise, we only found a significant effect on overall type of photos, $F(3,64)=3.42, p=.018, \eta^{2}=.05$ and $F(3,64)=33.21, p<.001, \eta^{2}=34$, respectively, but no interaction with the type of group.

\section{Effects of expectation of prejudice}

To explore the possible effects of Stigma Consciousness, Stigma Related Interpersonal Rejection, and Rejection Sensitivity scales on the choice of disgust, linear regression models were used for each type of photos (neutral, ambiguous with disgust, ambiguous with contempt, unambiguous) considering the type of group effect, participants' ratings on the scale and the interactions between these two variables as predictors. We did not find any effect of type of scale or any significant interaction between type of scale and group type.

\section{DISCUSSION}

Drawing upon previous research, we hypothesized that stigmatized individuals (TB patients in treatment) would see more negative emotions, particularly disgust, in the faces of others, in comparison to nonstigmatized individuals. Also, we explored the possible moderating role of prejudice expectations on emotion recognition.

We found a differential recognition of disgust between the two groups, although in the opposite direction, than hypothesized. Contrary to our expectation, our findings contradict our main hypothesis, that is, TB patients see less disgust, and not more, in the faces of others than the control group. We put two possible explanations forwards: First, as research has shown, people who suffer from stigma learn overtime to deal with it and, simultaneously, because they became more vigilant about the negative emotions routinely expressed by others, they experience a process of habituation and need a more intense facial expression to correctly identify the emotion (Hess et al., 1997). As shown by our results, it is in ambiguous photos involving disgust that TB patients (vs. the control group) attributed less disgust in the faces of others. Second, research on stereotype threat (Inzlicht et al., 2006; Steele \& Aronson, 1995) shows that its effects reduce cognitive resources and reduce targets' capacity, regulating their thoughts, behavior, and emotions, to perform well on cognitive and social tasks.

Moreover, people may be threatened even when they only suspect that their social identity can put them at risk of social devaluation, exclusion, and marginalization (Barreto, 2015; Crocker et al., 1998). When feeling threatened, people tend to distance themselves from emotion-related to stereotypical dimensions and relevant to the self as a defense form. We believe that patients' capacity to recognize the emotion of disgust might diminish because it is related to TB stereotypes. This can happen via two different processes. On the one hand, the draining of resources due to the chronic uncertainty of whether patients in TB treatment are discriminated against by their illness and, on the other hand, the active efforts to regulate their negative emotions during the challenging cognitive task of recognizing the right one (Inzlicht et al., 2006; Johns et al., 2008). Our research results align with this assumption since patients in treatment rated 
less disgust than the control group on all types of photos and mostly when disgust was the primary emotion displayed in the pictures.

Across the study, our data showed that TB patients chose more negative emotions than the control group, namely, sadness, fear, and anger. However, these results depend on the type of photos taken into account. Indeed, TB patients in treatment (compared with participants in the control group) attributed more sadness and fear and less happiness when rating neutral photos and chose more anger when ambiguous photos involving disgust were concerned. It is interesting to consider that a recent research endeavor pointed out that most, if not all, emotional expressions involve a degree of ambiguity and highlighted how contextual cues and individual idiosyncratic characteristics (e.g., membership in a particular group, internal states, etc.) are more important in shaping the appraisal of emotional stimuli than, for instance, the configuration of specific facial muscles (Bublatzky et al., 2020; Leppänen et al., 2004). For example, previous studies found that even "neutral" expressions can be differentially appraised, that is, recognizing an emotion when none (i.e., neutral stimuli) was supposedly presented (Hassin et al., 2013). It is not our intent here to debate the nature of what a "neutral" expression is. We consider it more meaningful to focus our interpretation on comparing the groups under study (i.e., stigmatized versus nonstigmatized individuals). Hence, we believe this experiment extends previous findings by providing new evidence that stigmatized individuals are biased in their perception of emotions, predicting a tendency to decode more negative emotions on the faces of others, especially emotions related to interpersonal rejection like fear and anger (Cottrell \& Neuberg, 2005; Stein et al., 2002).

Our findings support the reasoning that the fear of being socially devalued may lead stigmatized individuals to look for clues of rejection in the faces of others and to bias the emotion recognition in this particular context. Moreover, researchers have shown that psychological states can affect the perception of faces and facial affect (DeSteno et al., 2004; Niedenthal et al., 2000). For example, the emotions we feel can determine how long we see similar emotions last on someone else's face. TB patients have a very dangerous infectious disease that brings to their minds false beliefs and negative stereotypes related to it, about poverty, death, and hunger (Deribew et al., 2010; Vieira, 2011). Most likely, they also feel angry about and afraid of the consequences of having this disease on their and their families lives. These emotional states, or in other words, the emotions they feel, could lead them to detect more negative emotions on the faces of others (Niedenthal et al., 2000).

TB represents a threat to others' physical and psychological well-being and, therefore, the need to move away, avoiding a possible risk of infection. These feelings are expressed as rejection emotions like fear and anger (Marsh et al., 2005). TB patients are aware of this and expect to encounter these types of emotions in their lives. Therefore, they may be more vigilant in detecting fear and anger in the faces of others even when the situation is not threatening. This line of reasoning is consistent with our findings. Another negative emotion that has significance in our findings is sadness. TB patients in treatment attributed more sadness, especially in neutral photos, than in the control group. We also believe that they found this emotion often in their lives because sadness is associated with a permanent loss important and evokes sympathy and helping responses in others (Ambady \& Gray, 2002), so they are more alert to find sadness in the faces of others.

In our study, prejudice expectations did not moderate emotion recognition. We hypothesized that people in a stigmatized group who are more preoccupied with stigma would identify more faces expressing disgust than a control non-clinical group. Still, this hypothesis has not been confirmed in any of the analyses we have carried out. We think this is due to the sample size. This is one of the limitations of this study. Also, Cronbach's alphas for Stigma Consciousness Scale, Stigma Related Interpersonal Rejection Scale, and Rejection Sensitivity Scale are low in the control group. This could be due to the adaptation of these scales for non-stigmatized individuals. In future studies, both the sample size and the adaptation of scales must be considered carefully in such a complex sample.

Indeed, not only must the sample size of TB patients be considered, but the specificities of the control group must be taken into account; that is, the composition in terms of gender and age is slightly different between subsamples. For example, while the age mean is similar between the samples, its range is larger for TB patients. Future studies should equate the two subsamples in terms of participants' age and gender.

Another limit of this study is related to the selection of the experimental material. The chosen photos varied, taking into account gender and the type of expressions displayed. Considering the unambiguous photos, the number of male faces is not the same as the number of female faces; that is, three unambiguous negative emotions (contempt, disgust, and fear) were displayed only by males, while two unambiguous emotions (anger and happiness) were displayed only by females. Future studies should include an equal number of these types of photos by gender. Previous research highlighted that female faces are more attractive and more likable than male faces (Inzlicht et al., 2008). Notably, the number of neutral faces, ambiguous and unambiguous faces, has the same proportion of males and females represented in the 
pictures. Even though our main focus was on ambiguous faces and considered the other faces as a means of control, this matter should be considered carefully in future experiments. Despite the limitations of this study, and given the scarcity of studies assessing people's points of view from stigmatized groups in the perception of emotions, we believe it is a good starting point for future studies to consider. Our results confirm those of the only existing study to our knowledge and emphasize a biased perception of facial affect, extending this effect to a different stigmatized group.

\section{CONCLUSION}

As a WHO annual report recommended, addressing social determinants of TB is central in reducing TB deaths and incidence. The current research hypothesized that TB patients belong to a stigmatized group and have a bias in emotion recognition. Corroborating previous research on the consequences of stigma, our findings show that TB patients see more negative emotions on the faces of others, mostly emotions related to interpersonal rejection. This data provides insights into how these patients see their social world and how they relate to others in their social life.

However, the results of our study cannot be generalized to all stigmatized groups, nor to all stigmas related to physical or mental illness. The phenomenon of stigma in the context of disease is complex, contextual, and multidimensional and presents aspects that deserve future exploration to understand these processes better. Social Psychology's contribution to the understanding of disease dynamics is of paramount importance, as the leading causes of its spread have deep roots in group behavior and social perception.

\section{REFERENCES}

Ambady, N., \& Gray, H. M. (2002). On being sad and mistaken: Mood effects on the accuracy of thin-slice judgments. Journal of Personality and Social Psychology, 83(4), 947-961. https://doi.org/10.1037/0022-3514.83.4.947

Atre, S., Kudale, A., Morankar, S., Gosoniu, D., \& Weiss, M. (2011). Gender and community views of stigma and tuberculosis in rural Maharashtra, India. Global Public Health, 6(1), 56-71. https://doi.org/10.1080/17441690903334240

Bijlstra, G., Holland, R. W., Dotsch, R., Hugenberg, K., \& Wigboldus, D. H. J. (2014). Stereotype associations and emotion recognition. Personality and Social Psychology Bulletin, 40(5), 567-577. https://doi.org/10.1177/0146167213520458

Bublatzky, F., Kavcıoğlu, F., Guerra, P., Doll, S., \& Junghöfer, M. (2020). Contextual information resolves uncertainty about ambiguous facial emotions: Behavioral and magnetoencephalographic correlates. NeuroImage, 215(March), 1-12. https://doi.org/10.1016/j.neuroimage.2020.116814

Cottrell, C. A., \& Neuberg, S. L. (2005). Different emotional reactions to different groups: A sociofunctional threat-based approach to "prejudice." Journal of Personality and Social Psychology, 88(5), 770-789. https://doi.org/10.1037/0022-3514.88.5.770

Curtis, V., \& Biran, A. (2001). Dirt, disgust, and disease: Is hygiene in our genes? Perspectives in Biology and Medicine, 44(1), 17-31. https://doi.org/10.1136/jech.2007.062380

Daftary, A. (2012). HIV and tuberculosis: The construction and management of double stigma. Social Science \& Medicine, 74(10), 1512-1519. https://doi.org/10.1016/j.socscimed.2012.01.027

Darwin, C. (1965). The expression of the emotions in man and animals. University of Chicago Press. (Original work published 1872)

DeSteno, D., Dasgupta, N., Bartlett, M. Y., \& Cajdric, A. (2004). Prejudice from thin air. The effect of emotion on automatic intergroup attitudes. Psychological Science, 15(5), 319-324. https://doi.org/10.1111/j.0956-7976.2004.00676.x

Dotsch, R., Wigboldus, D. H. J., Langner, O., Knippenberg, A. Van, Dotsch, R., Wigboldus, H. J., Knippenberg, A. Van. (2008). Ethnic outgroup faces are biased in the prejudiced mind. Psychological Science, 19(10), 978-980. https://doi.org/10.1111/j.1467-9280.2008.02186.x

Dotsch, R., Wigboldus, D. H., Langner, O., \& Knippenberg, A. Van. (2008). Ethnic outgroup faces are biased in the prejudiced mind. Psychological Science, 19, 978-980. https://doi.org/10.1111/j.14679280.2008.02186.x

Dovidio, J. F., Major, B., \& Crocker, J. (2003). Stigma: Introduction and overview. In T. F. Heatherton, R. E. Kleck, M. R. Hebl, \& J. g. HULL (Eds.), The Social Psychology of Stigma (pp. 1-28). The Guildford Press.

Downey, G., \& Feldman, S. I. (1996). Implications of rejection sensitivity for intimate relationships. Journal of Personality and Social Psychology, 70(6), 1327-1343. https://doi.org/10.1037/00223514.70.6.1327

Ekman, P., Sorenson, E. R., \& Friesen, W. (1969). Pan-cultural elements in facial displays of emotion. Science, 
164(3875), 86-88. https://doi.org/10.1126/science.164.3875.86

Hess, U., Blairy, S., \& Kleck, R. E. (1997). The intensity of emotional facial expressions and decoding accuracy. Journal of Nonverbal Behavior, 21(4), 241-257. https://doi.org/https://doi.org/10.1023/A:1024952730333

Hassin, R. R., Aviezer, H., \& Bentin, S. (2013). Inherently ambiguous: Facial expressions of emotions, in context. Emotion Review, 5(1), 60-65. https://doi.org/10.1177/1754073912451331

Imhoff, R., Dotsch, R., Bianchi, M., Banse, R., \& Wigboldus, D. H. J. (2011). Facing Europe. Psychological Science, 22(12), 1583-1590. https://doi.org/10.1177/0956797611419675

Inzlicht, M., Kaiser, C. R., \& Major, B. (2008). The face of chauvinism: How prejudice expectations shape perceptions of facial affect. Journal of Experimental Social Psychology, 44(3), 758-766. https://doi.org/10.1016/j.jesp.2007.06.004

Inzlicht, M., McKay, L., \& Aronson, J. (2006). Stigma as ego depletion: How being the target of prejudice affects self-control. Psychological Science, 17(3), 262-269. https://doi.org/10.1111/j.14679280.2006.01695.x

Jittimanee, S. X., Nateniyom, S., Kittikraisak, W., Burapat, C., Akksilp, S., Chumpathat, N., ... Varma, J. K. (2009). Social stigma and knowledge of tuberculosis and HIV among patients with both diseases in Thailand. PloS One, 4(7), e6360. https://doi.org/10.1371/journal.pone.0006360

Johansson, E., Long, N. H., Diwan, V. K., \& Winkvist, a. (2000). Gender and tuberculosis control: perspectives on health seeking behaviour among men and women in Vietnam. Health Policy, 52, 33-51. https://doi.org/10.1016/S0168-8510(00)00062-2

Johns, M., Inzlicht, M., \& Schmader, T. (2008). Stereotype threat and executive resource depletion: Examining the influence of emotion regulation. Journal of Experimental Psychology: General, 137(4), 691-705. https://doi.org/https://dx.doi.org/10.1037/a0013834

Juniarti, N., \& Evans, D. (2011). A qualitative review: The stigma of tuberculosis. Journal of Clinical Nursing, 20(13-14), 1961-1970. https://doi.org/10.1111/j.1365-2702.2010.03516.x

Karim, F., Chowdhury, a. M. R., Islam, A., \& Weiss, M. G. (2007). Stigma, gender, and their impact on patients with tuberculosis in rural Bangladesh. Anthropology \& Medicine, 14(2), 139-151. https://doi.org/10.1080/13648470701381440

Langner, O., Dotsch, R., Bijlstra, G., Wigboldus, D. H. J., Hawk, S. T., \& van Knippenberg, A. (2010). Presentation and validation of the Radboud Faces Database. Cognition \& Emotion, 24(8), 1377-1388. https://doi.org/10.1080/02699930903485076

Leppänen, J. M., Milders, M., Bell, J. S., Terriere, E., \& Hietanen, J. K. (2004). Depression biases the recognition of emotionally neutral faces. Psychiatry Research, 128(2), 123-133. https://doi.org/10.1016/j.psychres.2004.05.020

Major, B., \& O'Brien, L. T. (2005). The social psychology of stigma. Annual Review of Psychology, 56, 393421. ttps://doi.org/10.1146/annurev.psych.56.091103.070137

Marsh, A. A., Ambady, N., \& Kleck, R. E. (2005). The effects of fear and anger facial expressions on approachand avoidance-related behaviors. Emotion, 5(1), 119-124. https://doi.org/10.1037/15283542.5.1.119

Matsumoto, D., Frank, M. G., \& Hwang, H. C. (2015). The role of intergroup emotions in political violence. $\begin{array}{llll}\text { Current Directions in Psychological Science, 24(5), 369-373. } & \text {. }\end{array}$ https://doi.org/10.1177/0963721415595023

Newheiser, A. K., \& Barreto, M. (2014). Hidden costs of hiding stigma: Ironic interpersonal consequences of concealing a stigmatized identity in social interactions. Journal of Experimental Social Psychology, 52, 58-70. https://doi.org/10.1016/j.jesp.2014.01.002

Niedenthal, P. M., Halberstadt, J. B., Margolin, J., \& Innes-Ker, Ä. H. (2000). Emotional state and the detection of change in facial expression of emotion. European Journal of Social Psychology, 30(2), 211-222. https://doi.org/10.1002/(SICI)1099-0992(200003/04)30:2<211::AID-EJSP988>3.0.CO;2-3

Oaten, M., Stevenson, R. J., \& Case, T. I. (2009). Disgust as a disease-avoidance mechanism. Psychological Bulletin, 135(2), 303-321. https://doi.org/10.1037/a0014823

Pinel, E. C. (1999). Stigma consciousness: The psychological legacy of social stereotypes. Journal of Personality and Social Psychology, 76, 114-128. https://doi.org/10.1037//0022-3514.76.1.114

Steele, C. M., \& Aronson, J. (1995). Stereotype threat and the intellectual test performance of African Americans. Journal of Personality Social Psychology, 69(5), 797-811. https://doi.org/http://dx.doi.org/10.1037/0022-3514.69.5.797

Stein, M. B., Goldin, P. R., Sareen, J., Zorrilla, L. T. E., \& Brown, G. G. (2002). Increased amygdala activation to angry and contemptuous faces in generalized social phobia. Archives of General Psychiatry, 59, 10271034. https://doi.org/10.1001/archpsyc.59.11.1027

Vieira, I. C. (2011). Contributos da "Liga Nacional contra a Tuberculose" para a luta antituberculose em 
Portugal (1899-1907). Encontro da Associação Portuguesa de HistóriaEconómica e Social, Coimbra. Wahl, O. F. (1999). Mental health consumers' experience of stigma. Schizophrenia Bulletin, 25(3), 467-478. https://doi.org/10.1093/oxfordjournals.schbul.a033394

Weiss, M. G., \& Ramakrishna, J. (2006). Stigma interventions and research for international health. Lancet, 367(9509), 536-538. https://doi.org/10.1016/S0140-6736(06)68189-0

World Health Organization (2017). Global tuberculosis report. Licence: CC BY-NC-SA 3.0 IGO.

$\begin{array}{ll}\text { Historial do artigo } & \\ \text { Recebido } & 08 / 2019 \\ \text { Aceite } & 01 / 2021 \\ \text { Publicado online } & 03 / 2021 \\ \text { Publicado } & 06 / 2021\end{array}$


Does TB stigma affect emotion recognition? 